\title{
PHENOMENOLOGICAL APPROACHES TO STUDY LEARNING IN THE TERTIARY LEVEL CHEMISTRY LABORATORY
}

\author{
Santiago Sandi-Urena* \\ School of Chemistry, University of Costa Rica, San Pedro de Montes de Oca, 2060, San José, Costa Rica
}

Recebido em 01/10/2017; aceito em 30/11/2017; publicado na web em 19/12/2017

\begin{abstract}
Despite the widespread notion amongst chemistry educators that the laboratory is essential to learn chemistry, it is often a neglected area of teaching and, arguably, of educational research. Research has typically focused on secondary education, single institutions, and isolated interventions that are mostly assessed quantitatively. It has also honed in on compartmentalised features instead of searching understanding of broader aspects of learning through experimentation. This paper contends there is a gap in subject specific, tertiary level research that is comprehensive and learning-centred instead of fragmented and instruction-based. A shift in focus requires consideration of methodological approaches that can effectively tackle the challenges of researching complex learning environments. This paper reckons qualitative approaches, specifically phenomenology, are better suited for this purpose. To illustrate this potential, it summarises an exemplar phenomenological study that investigated students' experience of change in instructional style from an expository (traditional) laboratory program to one that was cooperative and project-based (reformed). The study suggests the experience was characterised by a transition from a learning environment that promoted mindless behaviour to one in which students were mindfully engaged in their learning. Thus, this work puts forth the use of Mindfulness Theory to investigate and support design of laboratory experiences.
\end{abstract}

Keywords: laboratory instruction; tertiary education; phenomenology; chemical education; qualitative inquiry.

\section{INTRODUCTION}

Reform - understood as a significant change to improve what is perceived as not working effectively towards the desired goals- - has been a subject of debate for much of college chemistry education history. Already in 1929, Havighurst ${ }^{1}$ put forth his visionary proposal of shifting away from a curriculum and instructional approach that perpetuated students' "intellectual inertia". Although more focused on curriculum, his article clearly touched upon the need for revised teleology and pedagogical approaches in chemistry education. Such calls for reform continue to date., ${ }^{2,3}$ More surprisingly for many, debate on the role of the laboratory-the quintessential component of sound chemistry education-its purpose and its effectiveness to achieve learning outcomes began even before a dedicated publication in chemical education appeared. In 1915, in his article-Problems in the experimental pedagogy of chemistry-Spear ${ }^{4}$ stressed the need for systematic investigations to counter the common practice of making laboratory pedagogical decisions based on mere opinions. This debate clashes with the view of many for whom the methods of the traditional academic laboratory are unquestionable. In many instances, laboratory instruction has become subservient to lecture and reduced to a means to verify concepts covered in lecture and to develop manipulative skills. This-as Spear pointed out over a century ago - will be of little use unless the student continues on with a career in the chemical sciences.

A shared view of many researchers and review authors ${ }^{5-7}$ is that our understanding of learning of chemistry in academic experimental environments is simply insufficient. Or more candidly, that the "learning environment of the science laboratory is one of the areas that has been neglected by researchers". ${ }^{8}$ This lack of meaningful evidence has persisted over the years. ${ }^{9}$ To be clear, the target of

*e-mail: guillermo.sandiurena@ucr.ac.cr

This paper is part of the PubliSBQ Special Issue "IUPAC-2017" (http://publi.sbq.org.br/). criticism is not laboratory instruction itself but the practice of reaching pedagogical decisions guided by opinions or personal theories, often conveniently tied to the assumption what one does works just well even in the absence of supporting evidence thereof. ${ }^{10}$

This article intends to: (1) direct attention to the need for more educational research that is specific to learning in laboratory environments in tertiary chemical education; (2) to put forward the use of phenomenological approaches to advance research in the field; and (3) to exemplify the use of phenomenology.

\section{RESEARCH ON LEARNING IN THE LABORATORY AT TERTIARY LEVEL}

We have advocated elsewhere for research that specifically addresses learning chemistry in the academic laboratory in tertiary level. ${ }^{11}$ We have called attention to the limitations of three probable assumptions: that findings from research (a) at secondary level, (b) in other disciplines, and (c) in non-laboratory environments are transferable to learning chemistry in college academic laboratories. Secondary and tertiary education students are considerably different populations. Not only are college students a selected slice of the high school population in terms of their academic achievements but also different regarding their maturity stage, cognitive development, motivation, and expectations. In addition, they are exposed to particular socialization processes and other unique situational factors (e.g. their instructors are not necessarily pedagogically trained).

The particularities of teaching and learning chemistry in comparison with other disciplines are well acknowledged ${ }^{12}$ and are highlighted by findings of research in pedagogical content knowledge, PCK. ${ }^{13}$ By contrasting the fundamental differences between explaining a falling match — Physics — and a burning match —Chemistry-Bent ${ }^{14}$ eloquently exemplified the uniqueness of these disciplines. To make sense of such a "simple" chemistry phenomenon (macroscopic level), learners need to resort to theories relying on objects and behaviours that are not perceptible, that is, atoms and their bonds (sub-microscopic 
level). ${ }^{12}$ Often this level of abstraction becomes a hurdle in both, teaching and learning of chemistry. This difficulty arises directly from the nature of the discipline, thus it cannot possibly be addressed in other disciplines' learning environments.

In principle, the uniqueness of the learning experience in an academic laboratory is self-evident. When comparing practical experiences with other learning environments, Nakhleh, Polles, and Malina $^{6}$ argued the extensive complexity and information-richness of the chemistry laboratory pose unique challenges and affordances. Independently of the style of instruction, the laboratory places learners in direct interaction with peers, instructors, materials and instrumentation, all simultaneously and, even for traditional labs, in less structured environments than lecture. Likewise, in his review Hofstein ${ }^{5}$ makes a solid case for the chemistry laboratory as a "unique mode of learning, instruction and assessment".

Thus, despite valuable and informative, understanding of learning at secondary level, in other disciplines, and in non-laboratory environments may be rather limited in its applicability to learning in the college chemistry laboratory. Consensus within the chemistry education research community suggests there is need for sound research to significantly increase understanding of the role of laboratory instruction in learning chemistry. Nonetheless, research in this field continues to be neglected and "the role of the chemistry laboratory in student learning has gone largely unexamined". ${ }^{15} \mathrm{~A}$ study currently under way in our group provides further evidence of this research gap: the average yearly number of research articles published in English over the past 25 years is only slightly above five. Clearly, this modest research production conflicts with the presumed essential nature of the laboratory experience in learning chemistry. Furthermore, other bibliometric indicators such as citation connectivity and author productivity and persistence in the field hint issues extend beyond just the amount of publications. Eighty-six per cent of the authors in the database published a one-off paper and only six per cent have contributed more than two. ${ }^{16}$ Two eventual ramifications may be lack of expertise with only few groups consistently researching the field, and difficulties to achieve deep understanding of particular topics when investigations are not pursued over extended times and multiple studies. Thus, these obstacles make addressing big, challenging, tough research questions unlikely. Preliminarily, the aforementioned study suggests predominance of studies that utilise a piecemeal approach, focus on the implementation and assessment of pedagogies or short interventions (narrow approach), and favour study designs that use achievement on specific contents in the cognitive domain as measure variables (e.g. learning information). Nonetheless, trends over the past decade show authors publishing more consistently, more work on singular topics, and inclusion of qualitative traditions in the research methods, and consideration of non-cognitive variables and outcomes. Deciphering whether this trend is an artefact or a sustained trend will require time.

\section{ALTERNATIVE FRAMING OF RESEARCH ON LEARNING IN THE LABORATORY}

Learning in the laboratory is a fertile field for diverse research ideas. Authors have suggested and prioritised a variety of directions (e.g. Nakhleh, Polles \& Mallina). ${ }^{6}$ Nonetheless, the field presents intrinsic challenges that contribute in thwarting its development. Amongst these, methodological obstacles are of particular relevance. Research in the field has been characterised by the assessment of interventions made to laboratory environments without necessarily having prior specific evidence of the shortcomings of said environments. Commonly these interventions are of narrow scope and intend to influence a specific singular aspect of the environment. The multiple variables simultaneously affecting learning in the complex environment of academic science laboratories make it hard to imagine that tweaking just one variable could have a significant impact on student learning. ${ }^{17}$

We contend learning happens in all laboratory environments (i.e. instructional approaches), surely not necessarily with the same efficiency and to the same extent. Research could advance the field at greater pace if it aimed at gathering a fundamental and comprehensive understanding of broader aspects of the laboratory experience. Subsequently, understanding the active ingredients that support learning in its broad meaning and in multiple and diverse environments could guide pedagogical modifications more effectively. In this respect, Nakhleh and collaborators noted "the goal of research is to thoroughly understand what occurs in the laboratory and then work on revising curriculum and pedagogy". ${ }^{6}$

Already in 1982, Hofstein and Lunetta ${ }^{18}$ called attention to weaknesses in research design and implementation (e.g. confounding variables and insensitive instruments) that might mask learning outcomes. Likewise, a decade later Lazarowitz and Tamir ${ }^{19}$ argued for the need of research designs better suited to investigate the potential of laboratory learning. Referring to methodological approaches, Hodson ${ }^{10}$ emphasised the difficulty of reaching a conclusive answer to the questions about the pedagogic value of laboratory work unless research honed in on what students actually do in the laboratory, that is, on their lived experiences. Because of their nature, naturalistic research approaches (qualitative traditions) are more in tune to respond to this call for deeper understanding of experiences. ${ }^{20,21}$ Ultimately, "the effect or value of the laboratory experience might not be measurable in a quantitative sense" ${ }^{6}$ The evolution of chemical education research has responded to the emergence of more complex and engaged research questions with the advent of mixed-methods designs, as well as purely naturalistic studies. This trend has also permeated to research on learning in the laboratory.

Two overarching, foundational ideas condense the points made above. First, the broad, idea of seeking an enhanced understanding of what happens in academic laboratory environments to shed light on how learning takes place (or not) instead of focusing on fragmented and isolated variables and their effect on narrow outcomes. And second, a methodological perspective that calls for the use of naturalistic inquiry approaches that are better suited to address questions aimed at understanding how learning occurs.

Our group has worked on building a dedicated research programme to contribute in closing the research gap in learning in the chemistry laboratory at tertiary level. We have reported elsewhere the ways in which the foundational ideas above underlie premises in our research programme. ${ }^{11}$ We see phenomenology as the optimal naturalistic inquiry approach to address current research needs and to advance understanding in the field. Incidentally, a stance challenged by those who are sceptical of the feasibility of reducing experiences to a common essence. ${ }^{20}$ Following we present the rationale supporting this methodological proposition to conduct research on learning in laboratory environments.

\section{PHENOMENOLOGICAL APPROACHES TO STUDY LEARNING IN THE LABORATORY}

This section intends to introduce the tenets of phenomenology only to the extent needed to underscore its potential as a methodological tool. It does not pretend to be exhaustive and readers interested can find a more thorough discussion in key references. ${ }^{22-25}$ Table 1 summarises the key features of phenomenology. A precise distinction amongst the diverse naturalistic or qualitative methods can be sometimes challenging given the many definitions in current literature. ${ }^{24-26}$ In resolving this ambiguity, Patton ${ }^{24}$ suggests defining 
approaches based on the fundamental questions they address. For phenomenology he proposes: "What is the meaning, structure, and essence of the lived experience of this phenomenon for this person or group of people?" The notion there is an essence associated with a given experience is foundational for phenomenology, as much as culture is foundational for ethnography, to name an analogy. Clearly, it is the objective of the study what defines the lens of analysis and not vice versa. Thus, a single phenomenon can be examined using phenomenology or phenomenography, for instance, with the choice of methodology enormously affecting the information drawn and the conclusions reached. ${ }^{20}$ Patton defines the phenomenological essence as the "core meaning mutually understood through a phenomenon commonly experienced." Van Manen ${ }^{25}$ draws the gist of this definition: "Phenomenology asks... for that which makes a some-"thing" what it is-and without which it could not be what it is". The term phenomenology is polysemantic thus allowing interpretation as a philosophical tradition as much as a methodological approach. In alignment with our pragmatic research interests, we utilise phenomenology as an analytical instrument. We deem methods of qualitative inquiry stand-alone and applicable to research without having to engage in the philosophical discussions surrounding the tradition just the same way we do with quantitative methods. ${ }^{24}$ Quantitative research uses advanced statistical methods with no need to delve in the philosophical tenets of positivism, for instance. Likewise, analogies could be drawn for our use of spectroscopic techniques in chemistry research. Therefore, although the philosophical foundations of phenomenology infuse our work, we bypass the philosophical discussions and use phenomenology as an inquiry methodology.

Table 1. Phenomenology: Summary of key features

Definition: Phenomenology can be thought of as a philosophical discipline, an inquiry paradigm, an interpretative theory, a social science analytical perspective, a qualitative tradition, or a research methods framework in the naturalistic tradition. ${ }^{24}$ It is the latter that matches the intent of its use in this context.

Objective: To uncover the internal and invariant structure of a chosen phenomenon not in its empirical individuality but in its essence ${ }^{24}$; thus, providing access to understanding the meaning of said phenomenon by describing the lived experience as perceived by the participants. ${ }^{22}$

Essence: Core fundamental meaning shared by individuals of a commonly lived experience. ${ }^{24}$

Defining features: A phenomenological study (a) explicitly sets out to investigate the essence of a phenomenon; (b) investigates the lived experience (i.e. one can only know what one experiences), thus, it relies on first-hand recounts through in-depth interviews; (c) is retrospective, surfacing of the experience to consciousness shall not occur while the experience is occurring. ${ }^{23-25}$

Methodology: The pragmatic approach uses phenomenology as an inductive, analytical instrument to distil the essential description of a phenomenon. Phenomenological methods are stand-alone and may be utilised without engagement in the philosophical discussions surrounding the inquiry tradition. Despite having a common aim, phenomenologists may resort to procedural variants that better fit their perspectives. Nonetheless, the use of semi-structured interviews predominates across methodological approaches as source of data.

Outcome: Thick, rich description of the lived experience which allows further understanding of the experience.

Patton $^{24}$ identified three defining factors that clearly tease out phenomenology in contrast to studies that take a phenomenological perspective. First, essence is the cornerstone of phenomenology. Thus a phenomenological study must clearly make its objective to get at the essence of the phenomenon. Second, phenomenology investigates the lived experience. Phenomenology cannot rely on eyewitness accounts (e.g. direct observations); it is informed directly by the protagonists. Therefore, it gives the participants a voice through in-depth interviews. By doing so, the participants describe, explicate, and interpret their experience, a process through which they bring said experience to their consciousness. Ultimately, it is this engagement in meaning making what allows the individual to reach full understanding of what they experienced. Third, the nature of phenomenology is retrospective. Raising the experience to consciousness takes place only after it has come to completion. An immediate implication is that researchers should not interfere with the experience by interacting with the participants while the experience is under way.

In our view, current research paradigms commonly study the effectiveness of instructional interventions that are implemented in the laboratory as a response to an urge to somehow improve instruction. That is, the focus is on isolated aspects of instruction instead of broadly studying learning. We support reform of instruction towards practices that are aligned with our current understanding of how people learn and specifically with findings from research in chemical education. However, our understanding of learning in the laboratory is still scarce and fundamental research on learning needs to be advanced and should include the perspective of those experiencing learning. This proposed shift in focus comes with a concomitant need for new research approaches, which fortunately has been recently recognised by researchers. ${ }^{27,28}$ Thorough understanding in the complex learning environment of the chemistry laboratory is not achievable exclusively in the traditional quantitative sense. ${ }^{6}$

Similarly, realising the vast number of cognitive and noncognitive variables, interactions, and components in action in the laboratory, other dimensions of learning must be contemplated, e.g. the affective domain..$^{27,28}$ With this thorough understanding at hand, informed curricular and pedagogical decisions can be made and modifications designed to effectively promote the realisation of the potential of learning in experimental environments. In this context, we make a case for Casey's original proposal to use phenomenology to investigate learning in the chemistry laboratory. ${ }^{22}$

Unlike experimental approaches, naturalistic ones start off without hypotheses or theories to be falsified. They are rather hypothesis generating, with understanding and theories surfacing from fieldwork and data. In the case of phenomenology, it strictly hones in on revealing the internal and invariant essence of a phenomenon and not so in generating a theory or arguing a point. As we will see, the posterior use given to the output of a phenomenological study can take different directions in terms of further producing knowledge but this takes matters beyond the strictly defined phenomenological purpose. As an inductive and descriptive tool, phenomenology affords a unique viewpoint to understand how students interact with and within the complex learning environment and give their reality meaning. It is therefore through utilising this thorough understanding of the experience that we propose gaining a realistic perspective and understanding of learning in the laboratory is plausible. Thus, understanding learning in the lab is product of further analysing the output of the phenomenological approach and not its ultimate goal.

Even in its traditional formats, the chemistry academic laboratory is intrinsically a highly complex environment in which each student is exposed to interactions with individual peers, groups of peers, instructors, instrumentation and equipment, as well as knowledge. ${ }^{6}$ Many educational research methods, especially experimental, are limited in their ability to handle this multi-level complexity, just like, for instance, traditional chemical analysis approaches are limited to deal with highly complex chemical matrices. Phenomenology accounts for such complex social and environmental intricacies by allowing participants to develop meaning through a thick, rich 
description of their lived experience. This feature is something that definitely cannot be attained through experimental approaches and not necessarily by all qualitative methods. Another characteristic of utmost relevance in the use of phenomenology is the role of students as participants in research and not as subjects of research. Research designs that place students in the role of subjects onto whom actions are done, "may distort rather than disclose" what otherwise would be their natural behaviour. ${ }^{23}$ In phenomenology, the structure and essence of the experience emerges through the process of cocreation advanced by participants and researchers. Students actively contribute to the research endeavour by voicing their understanding of their own experience through the process of reliving and relating it. Complementarily, researchers are bestowed with reducing this recount through systematic textural and structural analyses. Ultimately, the integration and synthesis of these contributions comprise the output of the analysis: the essence of the experience.

Phenomenologists share a fundamental objective: extracting the essence of a phenomenon. Nonetheless, procedural approaches to accomplish this broad goal may vary according to researchers' perspectives. In our work, we model our procedure on the phenomenological analysis scheme proposed by Moustakas ${ }^{23}$ with only minor modifications. Figure 1 shows the fundamental stages of our research protocol. The rationale and the procedural details have been reported elsewhere. ${ }^{29,30}$

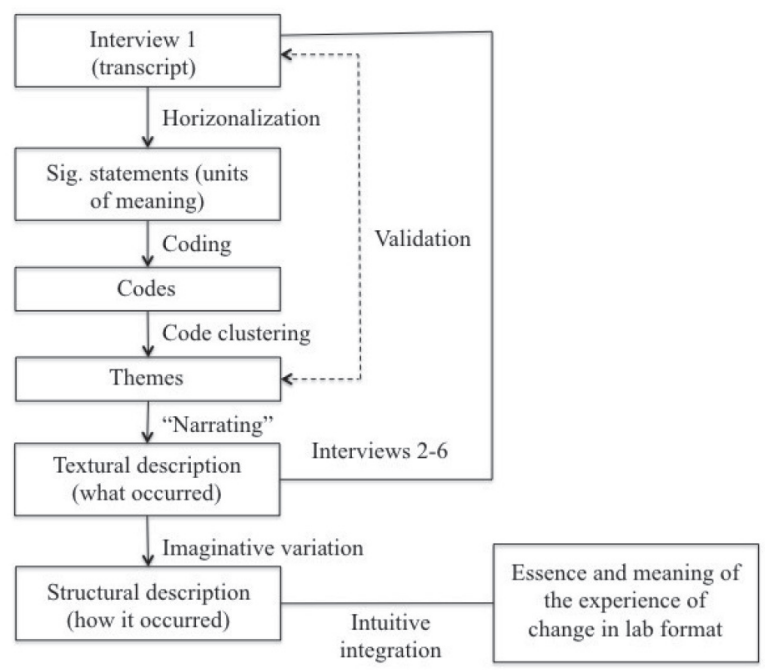

Figure 1. Protocol for the phenomenological reduction of textural data (Reproduced from Chopra et al. ${ }^{30}$ with permission of the Royal Society of Chemistry)

\section{SAMPLE PHENOMENOLOGICAL STUDY ON LEARNING IN THE CHEMISTRY COLLEGE LABORATORY}

So far, we have argued our current understanding of learning chemistry in academic experimental environments is only scant. In order to make substantial gains in this field, we put forth research that is specific to both chemistry and college level is essential. We reckon the use of naturalistic approaches advantageous and fruitful to overcome some of the inherent challenges of researching such complex learning environments. Amongst the naturalistic traditions available we endorse phenomenology. Our reports of phenomenological studies exploring the experiences of students and teaching assistants in diverse General Chemistry Laboratory programmes evince the potential of this approach to research the chemistry academic laboratory. ${ }^{29,31-34}$

Following, we summarise a recent phenomenology that illustrates our application of the methodology and the scope of its findings. In particular, this study exemplifies the potential of phenomenology as an exploratory tool and its hypothesis-generating nature. It is not its aim to answer closed questions but to derive from the in-depth exploration a series of new questions that in turn will guide the understanding of the phenomenon.

It is commonplace in research on learning in the lab that students experience only a short-time intervention or a single instructional style. Often this leads to cross-cohort and cross-instructional style comparisons. In contrast to this approach, participants in this study experienced a complete semester in each of two significantly different learning environments, one an expository, verificationtype programme centred on the contents and instructor-driven, the other, a cooperative problem-based programme that was student and learning-centred. The goal of the study was to distil the essence of the experience of undergoing such significant change in laboratory style from one that was expository (General Chemistry 1 ) to one that was problem-based (General Chemistry 2). A fundamental premise in embarking in this work was that the thorough description of the experience of change-as opposed to the experience of the separate instructional styles - would produce novel and divergent information from a new perspective. This information would subsequently grant access to better understanding of the contrasts and similarities between the learning environments and their individual gains, benefits, and weaknesses. It was not our purpose to gather evidence of the superiority of one instructional style over the other. We focused on using the experience of change to inform and enhance our understanding of learning in experimental environments. The nature of the information that would eventually emerge from this study was unique, especially in light of the rarity of having access to a cohort of students with this kind of experience. The methodological specifics of this study, as well as the in-depth description of the programmes can be found in Chopra et al. ${ }^{30}$

Figure 2 shows the three components of the outcome space obtained: (a) characterisation of the learning environments, (b) vectors of change, and (c) overarching descriptor of the change. The ability of students to accurately characterise learning environments was first reported in chemical education more than three decades ago. ${ }^{35} \mathrm{An}$ implication of this dimension is that over the course of a semester students develop a clear understanding of the environment in which they are immersed, thus, they may be able to knowledgeably gauge the efficacy and effectiveness of instruction. ${ }^{36,37}$ Whereas the ability of students to judge instruction has been called to question, this evidence invites reconsideration of the role of students' perspectives

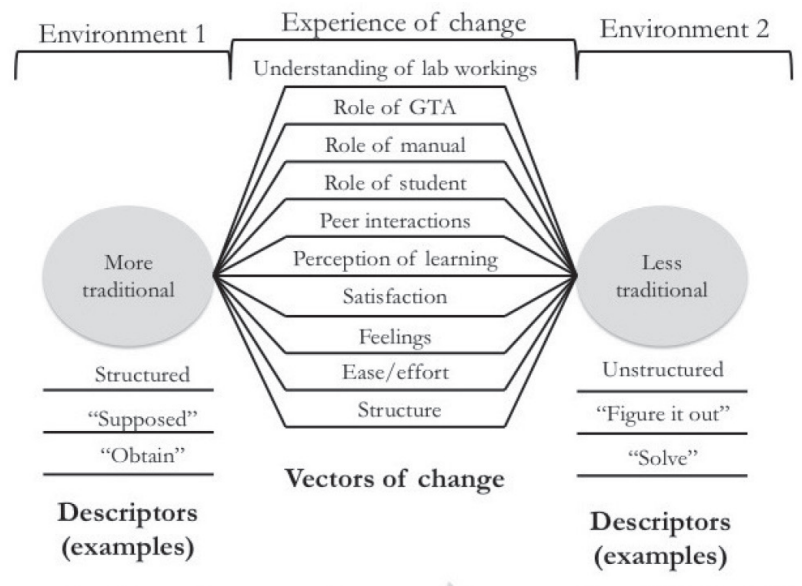

MINDLESSNESS

MINDFULNESS

Figure 2. Phenomenological outcome space (Reproduced from Chopra et al. ${ }^{30}$ with permission of the Royal Society of Chemistry) 
when evaluating courses and instructors. Furthermore, this dimension highlights the relevance of gathering fidelity evidence when studying learning environments. Studies that to some extent assume an automatic alignment between the designed and the enacted curricula may produce findings worth of scrutiny.

Data analysis led to ten fundamental vectors of change, that is, dimensions along which the students perceived change had occurred (Figure 2). These vectors are characteristic of the experience; therefore-unlike the valence attributed individually to the change along each of them-they are independent of instructional style preference. We describe the individual factors and their interpretation in Chopra et al. ${ }^{30}$ Here we present a couple of broad findings associated with the analysis of the vectors of change.

Besides cognitive factors (e.g. mathematical ability and prior knowledge), non-cognitive factors such as attitude have been studied in chemical education in terms of their ability to predict student achievement. ${ }^{38}$ Several of the vectors of change that emerged in this study are non-cognitive in nature and influence attitude towards the learning environment and subject. The relationship between attitude (or behavioural intent) and behaviour is complex and its discussion is beyond the boundaries of this report. Nonetheless, we want to stress instructors can take steps to effectively modify aspects that influence attitude, thereby, promoting behaviours that better support learning. ${ }^{38}$ The vectors of change in this study enable instructors and course designers to identify and understand such factors and to calibrate them so their influence may be better aligned with the desired outcomes.

Interestingly, the analysis of the vectors of change strongly suggests the default expectation for a college chemistry laboratory experience was aligned with the characteristics of an expository lab. In a recent study, three-fourths of participants' learning experiences in the chemistry laboratory were framed by their incoming expectations. ${ }^{28}$ Given that expectations potentially shape experiences, it is important to recognize the vectors along which students may experience imbalance, especially in laboratory programs that significantly differ from an expository model. The objective should not be to adjust the experience to the incoming expectations but to strategize accordingly (e.g. effective induction), thereby preventing a potentially disabling conflict (affective and cognitive). ${ }^{31}$ That students' expectations were in tune with expository lab instruction is meaningful in a broader sense, too. Often, college chemistry professors' only experience with high school learning was their own. This experience may be distant in time and nature. For instance, it is a fact an increasing proportion of US chemistry faculty comes from non-US secondary education systems. ${ }^{39}$ Students' entering expectations are firmly ingrained over a period of many years. These deeply rooted expectations (and concomitant attitudes and behaviours) may not be easily eradicated or modified. Instructors and course designers need to take these factors into consideration when pushing reform of any kind. Although convenient, it is neither reasonable nor realistic to assume students come to the laboratory as blank slates. Vectors of change inform instructors of possible unmet student expectations and the paths that may be followed to transition from them to the enactment of the desired experience. Furthermore, findings suggest the expectations set by the learning environment prompted students to behave in ways that were consistent with the objectives of the laboratory programmes, independently of their preferences for instructional styles.

Finally, the overarching descriptor that condenses the essence of experiencing the change in the laboratory instructional style is a shift from mindless behaviour to mindfully engaging in the learning environment. We arrived at this finding through thorough analysis of the participant evidence and through in-depth analysis of our own processing of data.
Phenomenology strives to distil what makes a some-"thing" what it is and without which it would not be what it is. ${ }^{25} \mathrm{~A}$ mainstay of this study is defining the phenomenon as the change in instructional approach in opposition to a singular instructional approach or learning environment. By doing so, the information derived offered an alternative and untried perspective to learning in the college chemistry laboratory. The same participants compared and contrasted two different learning environments through the process of re-living their experiences. For this cohort of students, the change in the laboratory instructional style - the phenomenon-was defined by the transformation of their relationship with the learning environment from one that was mindless in nature to one that was mindfully engaged. This feature is characteristic of the phenomenon and unrelated to student preference for instructional style and, very importantly, it is grounded in the data. ${ }^{30}$

As mentioned above, phenomenology affords a unique perspective to understand students' experiences through the elucidation of their essence. From this perspective, researchers can access enhanced understanding of learning in the laboratory environment, not from phenomenology itself but through subsequent analysis of its output. It is here, we believe, where the potential of phenomenology truly resides. Thus, understanding the essence of the change in instructional styles in this study prompted us to analyse the two learning environments separately and comparatively in terms of their ability to promote mindless or mindful engagement. In doing so, we came across the Mindfulness Theory put forth by Professor Ellen J. Langer. ${ }^{40,41}$ The construct of mindfulness and its counterpart, mindlessness, were introduced in social psychology in the 1970s and have been utilised in many areas, including educational research. ${ }^{42}$ Langer and Moldoveanu ${ }^{43}$ conceptualise mindfulness as the subjective feel of a "heightened state of involvement and wakefulness or being in the present". Mindfulness entails awareness of the context and perspective of one's own actions, and openness to the possibility of diverse perspectives. ${ }^{40}$ In addition, when mindfully engaged, the individual is open to receive and to process new information. In contrast, mindlessness is characterised by a state of mind in which behaviour is context-dependent, and the individual is oblivious of alternative perspectives and novel aspects of the situation. Mindlessness is associated with processing with little or no conscious awareness, or acting on autopilot. ${ }^{44}$ Table 2 . summarises the key aspects associated with the construct of mindfulness.

Studies in multiple fields have supported the tenets of the Mindfulness Theory and have provided insights into the conditions that promote mindfulness. The associated benefits range from physical to cognitive. The role of mindfulness in education is patent given its definition and attributes. In fact, educational philosophers, policy makers, and practitioners have unmistakably highlighted its relevance since the turn of the 21 th Century. ${ }^{42}$ We became particularly interested in identifying educational practices that nurture mindfulness as a trait and not only as a short-term response to an environmental stimulus. In their work, Ritchhart and Perkins ${ }^{42}$ have summed up three such practices: (a) looking closely or the active engagement in examining a task or material with the disposition to discover new information, (b) exploring possibilities and potentially diverse perspectives, and (c) utilising ambiguity as conditional instruction in place of absolute instruction that presents facts as indisputable.

In current work, we are characterising both laboratory programmes in this study according to their ability to prompt students' disposition towards engaging mindlessly or mindfully in their experience. This task entails re-analysing participant interviews using this time around the tenets of Mindfulness Theory and the practices framed by Ritchhart and Perkins..$^{42}$ This work, which derives as an extension from the study presented here, exemplifies how 
Table 2. Key aspects associated with mindfulness

\begin{tabular}{|c|c|}
\hline $\begin{array}{l}\text { Mindfulness: } \\
\text { Heightened state of involvement } \\
\text { and wakefulness or being in the } \\
\text { present }\end{array}$ & $\begin{array}{c}\text { Mindlessness: } \\
\text { Processing with little or no } \\
\text { conscious awareness, or acting on } \\
\text { autopilot }\end{array}$ \\
\hline \multicolumn{2}{|c|}{ Contrast of factors that promote mindfulness/mindlessness in education ${ }^{40,43}$} \\
\hline Mindfulness & Mindlessness \\
\hline Situated in the present & $\begin{array}{l}\text { Reliance upon distinctions and cat- } \\
\text { egories drawn in the past }\end{array}$ \\
\hline Awareness of context and perspective & Rules and routines \\
\hline $\begin{array}{l}\text { Self-control, planning, making deci- } \\
\text { sions }\end{array}$ & $\begin{array}{l}\text { Over-structured, fool-proofed ex- } \\
\text { periences }\end{array}$ \\
\hline Conditional instruction & Perspective-free instruction \\
\hline $\begin{array}{l}\text { Variation of stimuli, change, ques- } \\
\text { tioning }\end{array}$ & $\begin{array}{l}\text { Learning the basics, devoted atten- } \\
\text { tion to a single aspect }\end{array}$ \\
\hline \multicolumn{2}{|c|}{ Benefits of mindfulness ${ }^{40}$} \\
\hline \multicolumn{2}{|c|}{$\begin{array}{l}\text { Awareness of the context, flexible transfer of skills and knowledge to new } \\
\text { situations }\end{array}$} \\
\hline \multicolumn{2}{|c|}{ Perspective of own actions and possibility of diverse perspectives } \\
\hline \multicolumn{2}{|c|}{ Receptiveness to new information and to process it } \\
\hline \multicolumn{2}{|l|}{ Support of critical and creative thinking } \\
\hline \multicolumn{2}{|l|}{ Development of deep understanding } \\
\hline Enhanced motivation and engagemer & \\
\hline
\end{tabular}

Looking closely: Active engagement in examining a task or material with the disposition to discover and process new information

Exploring possibilities and perspectives: Considering the viewpoints and arguments of others and alternative explanations.

Conditional instruction: Ambiguity introduced by design in place of absolute instruction that presents facts as indisputable (not to be interpreted as lack of planning leading to confusing instructions, for example).

phenomenology informs research and understanding of learning. In parallel, we are using this same lens to re-analyse other researchers' work. To this end, we are using published and otherwise available student quotes from others' research and subjecting these quotes to the coding system we are applying to re-analyse our original data. That is, we are using Mindfulness Theory as an umbrella concept or unifying lens to re-examine published work and to aggregate the qualities of learning environments that have successfully led to desirable outcomes. Our working premise is that we will be able to connect successful reform in the chemistry laboratory with practices associated with environments that promote mindfulness. By drawing studies from multiple and varied institutions with diverse student populations and whose evidence was gathered over an extended period of time, we seek to distinctively strengthen the generalizability and transferability of our findings.

In addition, we maintain the fundamentals of Mindfulness Theory that are more accessible to conceptualise and to integrate to instructional design than other theoretical frameworks. We believe transfer of research findings into practice via reform is hampered if chemistry educators who do not possess a formal background in pedagogy are unintentionally alienated by theories they may deem excessively intricate. Evidence shows easily modifiable features of a learning environment can be adjusted based on the fundamental ideas of Mindfulness Theory to produce greater mindfulness and to reap its benefits. ${ }^{42}$ Thus, integrating these research findings may be more appealing to chemistry instructors.

\section{CONCLUSION}

We have argued our understanding of learning in the academic chemistry laboratory at college level is only scant. We associate this gap in knowledge with the lack of sufficient research and with the qualities of the research that is done and the nature of the questions addressed. ${ }^{11}$ That research done in this area continues to be marginal contradicts the broadly accepted central stage occupied by the academic laboratory in chemical education. In fact, referring to science laboratories, Hofstein \& Lunetta ${ }^{5}$ asserted in their 2004 review that only "sparse data from carefully designed and conducted studies" supported the notion laboratory is essential to understand science. Evidently, this is a criticism of the body of research and not a suggestion laboratory should be discontinued from chemistry education. Most chemistry educators would agree it is through doing chemistry that we can potentially reach students and engage them in deep learning. Leaving out the hands-on experience is for all purposes unthinkable. Yet, our understanding of what goes on in the learning laboratory is minimal and our efforts to reach considerable understanding through sound research are only modest.

In this paper we have briefly presented our thoughts and attempts to contribute in closing the gap in research on learning in the chemistry college laboratory. We believe a major obstacle is methodological, therefore, we propose the use of phenomenological approaches as a research tool. In our view, naturalistic methods are suited to investigate such complex environments and we hope to awaken interest in others to delve in the challenge of conducting research in this field and of using phenomenological methods for that purpose. Qualitative inquiry is exploratory and hypothesis generating. ${ }^{21}$ Consistent with this nature, use of phenomenology as a lens of analysis led us to insights into what happens in the laboratory, and these have subsequently guided us to Mindfulness Theory. We propose turning to this theoretical framework to further analyse learning environments as a whole, and specific strategies where they have been employed. Furthermore, Mindfulness Theory lends itself as a useful tool to complement instructional design of laboratory programmes. This is especially relevant given the current interest in supporting the development of mindfulness as a trait and not only as a response to isolated instantiations. The chemistry laboratory is a continuous experience sustained for several months; therefore, it may constitute an ideal environment to promote mindfulness as a trait in educational environments. We believe this article contributes to inform the discussion on learning in the tertiary chemistry laboratory and we hope it broadens chemistry educators' views and understanding in this field.

\section{ACKNOWLEDGEMENTS}

The author thanks Starbucks ${ }^{\circledR}$ for providing a tranquil working environment at its stores where this article was written.

\section{REFERENCES}

1. Havighurst, R. J.; J. Chem. Educ. 1929, 6, 1126.

2. Towns, M. H; Kreke, K.; Fields, A.; J. Chem. Educ. 2000, 77, 111.

3. Eilks, I.; Byers, B. In Innovative Methods of Teaching and Learning Chemistry in Higher Education; Eilks, I., Byers, B., eds.; RSC Publishing: London, 2009, pp. 5-22.

4. Spear, E. B.; J. Educ. Psych. 1915, 6, 231.

5. Hofstein, A.; Lunetta, V. N.; Sci. Educ. 2004, 88, 28.

6. Nakhleh M.B.; Polles J.; Malina E. In Chemical Education: Towards Research-based Practice; Gilbert, J. K., De Jong, O., Justi, R., Treagust, D. F., Van Driel, J. H., eds.; Springer: Dordrecht, 2003, cap. 4.

7. Reid, N.; Shad, I.; Chem. Educ. Res. Pract. 2007, 8, 172. 
8. Hofstein, A.; Cohen, I.; Lazarowitz, R.; Research in Science \& Technological Education 1996, 14, 103.

9. Elliott, M. J.; Stewart, K. K.; Lagowski, J. J.; J. Chem. Educ. 2008, 85, 145 .

10. Hodson, D.; Educ. Quim. 2005, 16, 30.

11. Sandi-Urena, S.; Chrzanowski, M. In Science Education Research and Practical Work; Eilks, I., Markic, S., Ralle, B., eds; Shaker Verlag: Aachen, 2016, pp. 181-192.

12. Floriano, M. A.; Reiners, C. S.; Markic, S.; Avitabile, G. In Innovative Methods of Teaching and Learning Chemistry in Higher Education; Eilks, I., Byers, B., eds.; RSC Publishing, 2009, pp. 23-42.

13. Bucat, R., Chem. Educ. Res. Pract. 2004, 5, 215.

14. Bent, H. A., J. Chem. Educ. 1986, 63, 151.

15. Singer, S. R.; Nielsen, N. R.; Schweingruber, H. A. In Disciplinebased education research: understanding and improving learning in undergraduate science and engineering; Singer, S. R., Nielsen, N. R., Schweingruber, H. A., eds.; National Academies Press: Washington, 2012, pp. 6-11.

16. Sandi-Urena, S. Unpublished work.

17. Chang, H-P.; Lederman, N. G.; J. Res. Sci. Teach. 1994, 31, 167.

18. Hofstein, A.; Lunetta, V. N.; Rev. Educ. Res. 1982, 52, 201.

19. Lazarowitz, R.; Tamir, P. In Handbook of Research on Science Teaching and Learning; Gabel, D., ed.; Mcmillan: New York, 1994, pp. 94-128.

20. Bodner, G. M.; Physics Education Research Conference, Sacramento, CA, 2016, DOI: 10.1119/perc.2016.plenary.001

21. Bodner, G. M. In Theoretical frameworks for research in chemistry/ science education; Bodner, G. M., Orgill, M., eds; Pearson Education, Inc.: Upper Saddle River, 2007, pp. 3-27.

22. Casey, K. In Theoretical frameworks for research in chemistry/science education; Bodner, G. M., Orgill, M., eds; Pearson Education, Inc.: Upper Saddle River, NJ, 2007, pp. 122-131.

23. Moustakas, C.; Phenomenological research methods, Sage Publications: Thousand Oaks, CA, 1994.

24. Patton, M. Q.; Qualitative research \& evaluation methods, Sage Publications: Thousand Oaks, 2002.
25. Van Manen, M.; Researching lived experience: Human science for an action sensitive pedagogy, The University of Western Ontario: London, 1990.

26. Creswell, J. W.; Qualitative inquiry and research design: Choosing among five approaches, Sage Publications: Los Angeles, 2012.

27. Galloway K. R.; Bretz, S. L.; J. Chem. Educ. 2015, 92, 1149.

28. Galloway K. R.; Bretz S. L.; Chem. Educ. Res. Pract. 2015, 16, 879.

29. Sandi-Urena, S.; Cooper, M. M.; Gatlin, T. A., Chem. Educ. Res. Pract. 2011, 12, 92 .

30. Chopra, I.; O'Connor, J.; Pancho, R.; Chrzanowski, M., Sandi-Urena, S., Chem. Educ. Res. Pract. 2017, 18, 113.

31. Sandi-Urena, S.; Cooper, M. M.; Gatlin, T. A.; Bhattacharyya, G.; Chem. Educ. Res. Pract. 2011, 12, 434.

32. Sandi-Urena, S.; Cooper, M.; Stevens, R.; J. Chem. Educ. 2012, 89, 700.

33. Sandi-Urena, S.; Gatlin, T. A.; Educ. Quim. 2012, 23, 141.

34. Sandi-Urena, S.; Gatlin, T.; J. Chem. Educ. 2013, 90, 1303.

35. Abraham, M. R.; J. Res. Sci. Teach. 1982, 19, 155.

36. Bergin, A.; Sharp, K.; Gatlin, T.; Villalta-Cerdas, A.; Gower, A.; SandiUrena, S.; J. Chem. Educ. 2013, 90, 289.

37. Villalta-Cerdas, A.; McKeny, P.; Gatlin, T.; Sandi-Urena, S.; Assessment \& Evaluation in Higher Education, 2015, 40, 181.

38. Xu, X.; Villafane, S. M.; Lewis, J. E.; Chem. Educ. Res. Pract. 2013, 14 , 188.

39. Sestilio, M.; Gatlin, T. A.; Villalta-Cerdas, A.; Sandi-Urena, S.; 245th American Chemical Society National Meeting, New Orleans, Louisiana, USA, 2013

40. Langer, E. J.; The power of mindful learning, Addison-Wesley Publishing Company: Reading, 1997.

41. Langer, E. J.; Current Directions in Psychological Science 2000, 9, 220.

42. Ritchhart, R.; Perkins, D. N., J. Soc. Issues 2000, 56, 27.

43. Langer, E. J.; Moldoveanu, M., J. Soc. Issues 2000, 56, 1.

44. Demick, J.; J. Soc. Issues 2000, 56, 141. 